\title{
La fitoterapia como fuente de medicamentos reguladores del metabolismo tumoral $y$ activadores de la respuesta inmunitaria
}

\author{
Susana Fiorentino ${ }^{1, *}$, Claudia Urueña ${ }^{1}$ \\ ${ }^{1}$ Grupo de Inmunobiología y Biología Celular, Pontificia Universidad Javeriana, Bogotá, D.C., Colombia \\ Artículo de posesión para el ingreso como miembro correspondiente a la \\ Academia Colombiana de Ciencias Exactas, Físicas y Naturales el 1 de junio de 2017
}

\begin{abstract}
Resumen
El término cáncer integra un grupo de enfermedades complejas que responden a múltiples factores y se manifiestan de forma diferente según el órgano afectado o el mecanismo molecular implicado. En términos generales, se presenta una alteración en los mecanismos que regulan el crecimiento de las células, lo cual genera proliferaciones incontroladas que rompen la homeóstasis normal del organismo y afectando no solo el órgano blanco sino a todo el organismo. La búsqueda de terapias contra el cáncer se basa en el conocimiento de estos mecanismos moleculares y sus innumerables consecuencias. En esta revisión se recogen los estudios realizados y publicados por nuestro grupo de investigación en los últimos 13 años en torno a Caesalpinia spinosa (Molina) Kuntze y Petiveria alliacea Linne (Phytolaccaceae), así como algunos datos aún no publicados. La revisión se centra en los mecanismos relacionados con el metabolismo energético tumoral y la regulación de la respuesta inmunitaria, así como en los últimos procedimientos requeridos para llevar a cabo el primer ensayo clínico de fase I para un medicamento contra el cáncer en Colombia. (C) 2018. Acad. Colomb. Cienc. Ex. Fis. Nat.
\end{abstract}

Palabras clave: Cáncer; Fitomedicamentos; Metabolismo tumoral; Respuesta inmune antitumoral; Anamú; Dividivi.

Phytotherapy as a source of medicaments that regulate tumoral metabolism and activate the immune response

\begin{abstract}
Cancer is the name for a group of complex and multifactorial diseases that manifest differently depending on the organ affected or the molecular mechanism involved. In general terms, there is an alteration in the mechanisms that regulate cell growth, generating their uncontrolled proliferation, which breaks the normal homeostasis of the organism, affecting not only the target organ, but the individual in general. The search for therapies against cancer is based on the knowledge of these molecular mechanisms and their countless consequences. In the present review, we include the work done and published in our research group during the past 13 years on Caesalpinia spinosa (Molina) Kuntze and Petiveria alliacea Linne (Phytolaccaceae), as well as some data not yet published. The review focuses on the mechanisms related to tumor energy metabolism and the regulation of the immune response, as well as the latest procedures that will allow us to conduct the first phase I clinical trial for a cancer drug in Colombia. (C) 2018. Acad. Colomb. Cienc. Ex. Fis. Nat.
\end{abstract}

Key words: Cancer; Phytomedicaments; tumor metabolism, antitumor immune response; Anamu; Dividivi.

\section{El metabolismo de las células tumorales}

Una de las características de las células tumorales es su alta tasa de proliferación, la cual induce un aumento en el consumo de glucosa y glutamina, entre otras fuentes de energía, necesario en la producción del carbono requerido para la construcción de nuevas macromoléculas. Además, mediante la oxidación se generan otros factores como el dinucleótido de nicotinamida y adenina (NADH) o el dinucleótido de flavina y adenina $\left(\mathrm{FADH}_{2}\right)$, los cuales median la transferencia de electrones a la cadena respiratoria para permitir la síntesis del trifosfato de adenosina (ATP), indispensable para la supervivencia energética de la célula.
El alto consumo de glucosa de las células tumorales fue registrado inicialmente por Otto Warburg (1956), trabajo que le mereció el Premio Nobel de Medicina en 1931 y cuyos resultados aportaron considerablemente al estudio del cáncer y la búsqueda de nuevas terapias (Koppenol, et al., 2011). Estos hallazgos sirvieron de base para el desarrollo de la tomografía de emisión de positrones (TEP), la cual se basa en el consumo de la ${ }^{18} \mathrm{~F}$-fluodeoxiglucosa $\left({ }^{18} \mathrm{~F}-\mathrm{FDG}\right)$,

\footnotetext{
*Correspondencia:
}

Susana Fiorentino; Susana.fiorentino@javeriana.edu.co

Recibido: 20 de octubre de 2017

Aceptado: 3 de abril 2018

Editor: Luis Fernando García 
ampliamente utilizada para el diagnóstico y seguimiento de un gran número de tumores de metabolismo glucolítico (Almuhaideb, et al., 2011). La glutamina, por su parte, provee el nitrógeno necesario para la síntesis de nucleótidos de pirimidinas y purinas, de la glucosamina-6-fosfato y de los aminoácidos no esenciales. Su alto consumo en las células tumorales se ha documentado ampliamente y, más recientemente, se ha sugerido el uso de la ${ }^{18} \mathrm{~F}$-glutamina como trazador del crecimiento tumoral cuando la glucosa no constituye un buen marcador (Lieberman, et al., 2011; Venneti, et al., 2015).

El papel de la glucosa como una de las principales fuentes de energía de las células tumorales, se ha relacionado con la poca capacidad mitocondrial observada en algunos tumores; sin embargo, algunos datos recientes muestran que la mitocondria de las células tumorales funciona muy bien y que, de hecho, las razones para que una célula tumoral consuma más glucosa se relacionan más con la capacidad de la glucólisis de participar en la generación de metabolitos intermediarios de múltiples procesos biosintéticos con la generación de ATP. Es así que el desacoplamiento de la glucólisis de la cadena respiratoria no parece tener un efecto importante en la célula tumoral, la cual favorece la producción de lactato a partir del piruvato mediante procesos de adaptación metabólica, lo que disminuye la entrada del piruvato al ciclo del ácido tricarboxílico (Pavlova \& Thompson, 2016) y, por ende, protege de la sobrecarga energética. En la Figura 1 se presentan las diferencias entre el metabolismo energético de las células tumorales y las normales.
Aunque los tumores han desarrollado un sinnúmero de desviaciones metabólicas para protegerse del exceso de electrones generados por este metabolismo acelerado, que muchas veces exceden la capacidad de la ATP sintasa, es inevitable la formación de una gran cantidad de especies reactivas del oxígeno (ERO) en el microambiente tumoral. De hecho, estas especies intracelulares provienen de la mitocondria y del retículo endoplásmico, así como de la activación de las $\mathrm{NAD}(\mathrm{P}) \mathrm{H}$ oxidasas (Cairns, et al., 2011), y cuando aumentan, particularmente el peróxido de hidrógeno $\left(\mathrm{H}_{2} \mathrm{O}_{2}\right)$, dañan la estructura de las macromoléculas celulares, fenómeno que se denomina estrés oxidativo (Sullivan \& Chandel, 2014). En las células tumorales, este estrés oxidativo es controlado por la alta producción de enzimas antioxidantes mediante un mecanismo principal que conlleva la activación del factor nuclear (derivado de eritroide 2) similar al 2 (Nuclear erythroid 2-related factor, NRF2), el cual participa en la regulación de la expresión de múltiples genes antioxidantes (Sullivan \& Chandel, 2014). Muchos de los tumores tienen mutaciones en este factor y, en consecuencia, presentan una marcada expresión constitutiva de muchas de las enzimas detoxificantes, lo que hace que, en términos generales, el nivel de ROS tumoral este elevado dado que ellas pueden tolerar una carga de ERO superior a la de las células normales. Este exceso de ERO, puede conllevar algunas veces al fenómeno denominado senescencia inducida por oncogenes (SIO) (CourtoisCox, Jones, Cichowski, 2008), el cual está relacionado con la expresión de una mutación de $B R A S$ o $R A F$ que inhibe la proliferación tumoral en presencia de las ERO. La
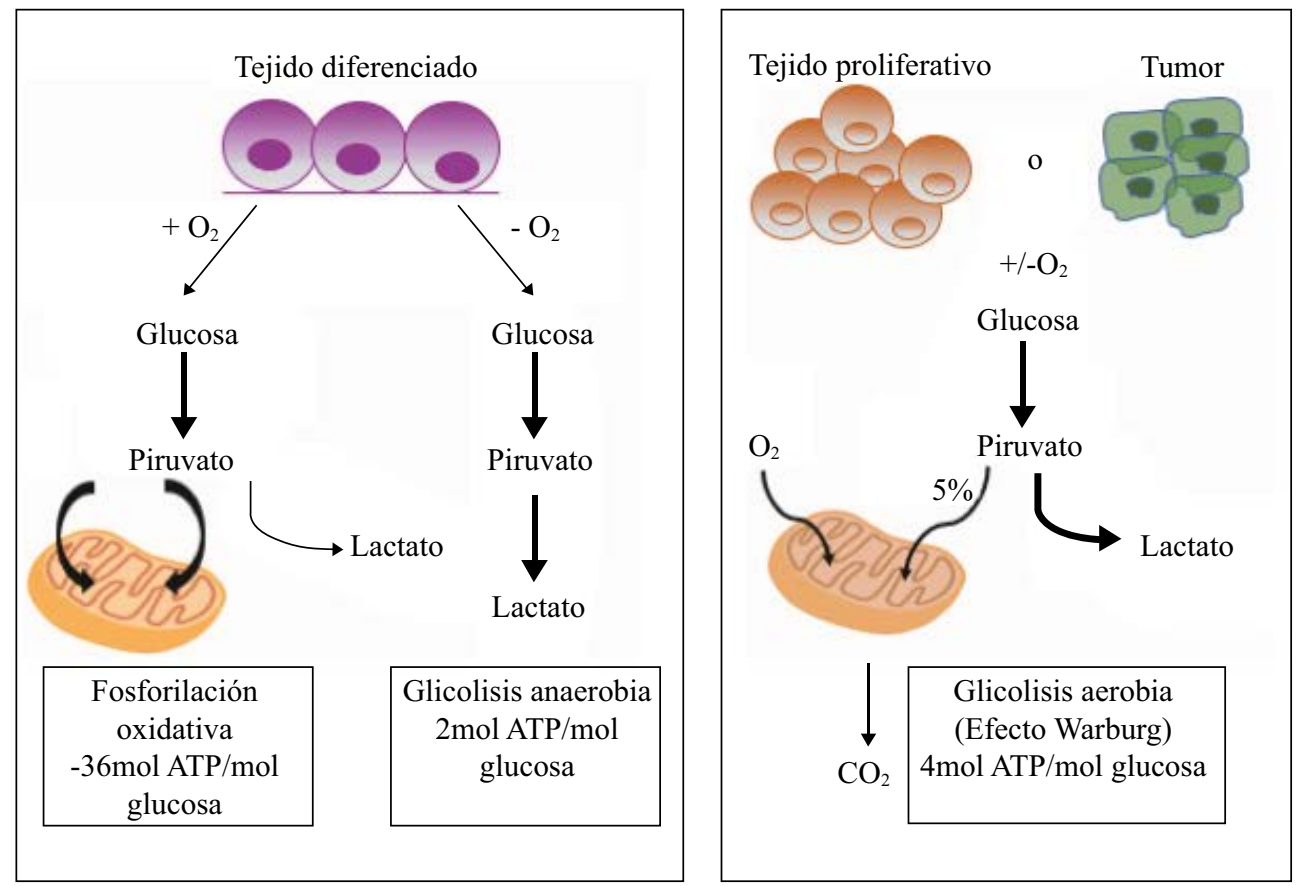

Figura 1. Representación esquemática del metabolismo en un tejido diferenciado (células normales) en comparación con un tejido proliferativo o tumoral. Modificado de JF Hernández. Tésis de Doctorado. 
disminución de dicha senescencia puede potenciar la génesis de los tumores (Kaplon, et al., 2013), así como el uso de algunos antioxidantes, lo cual se discutirá más adelante. Es decir que no siempre la disminución de las ERO tumorales tiene un efecto benéfico, lo cual sugiere que se da un delicado equilibrio que debe mantenerse al interior del tejido tumoral. Las ERO, entonces, tienen un papel dual en la génesis tumoral, ya que su sobreproducción es deletérea para la célula eucariótica y, en contraste, cuando su concentración es baja resultan necesarias para mantener dicha génesis (Sullivan \& Chandel, 2014).

Teniendo en cuenta estos antecedentes metabólicos, puede decirse que la diversidad tumoral se explica por la proliferación incontrolable de poblaciones de células, en principio glucolíticas, conjuntamente con poblaciones quiescentes, las cuales son menos glucolíticas y utilizan mucho más la fosforilación oxidativa. Entre éstas están, además, las células madre tumorales (CMT) que, por su propia naturaleza, expresan bombas de resistencia a drogas y otros mecanismos detoxificantes, lo cual les permite vivir en ambientes hostiles y con bajas concentraciones de oxígeno. Esta población es la responsable principal de las metástasis y de la resistencia tumoral a la quimioterapia (Dave, et al., 2012; Margaryan, et al., 2017). El conocimiento de su relación con el microambiente tumoral abre la posibilidad de estudiar terapias que regulen tales interacciones (Plaks, et al., 2015), así como la resistencia a drogas, entre ellas, los medicamentos naturales (Cort \& Ozben, 2015).

\section{El metabolismo tumoral y su relación con la respuesta inmunitaria}

El metabolismo tumoral oscila entre la glucólisis y la fosforilación y puede afectar seriamente el microambiente tumoral. El alto consumo de glucosa y glutamina genera una acumulación de lactato extracelular, el cual produce, a su vez, un ambiente ácido e inmunosupresor que atenúa la activación de las células dendríticas, los linfocitos $\mathrm{T}$ y las células asesinas naturales (natural killer, NK), y favorece la generación de células supresoras de tipo mieloide o linfoide (Colegio, et al., 2014; Fischer, et al., 2007; Goetze, et al., 2011; Husain, et al., 2013). Por otra parte, el aumento de lactato incrementa la angiogénesis y estimula la producción de ácido hialurónico por parte de los fibroblastos, lo que favorece el crecimiento y la invasión tumoral (Pavlova \& Thompson, 2016). Estos hallazgos ponen en evidencia el hecho de que el control del metabolismo tumoral podría tener un efecto benéfico no solo en la evolución misma del tumor sino en la generación de una efectiva respuesta inmunitaria antitumoral

Por otra parte, la inflamación está implicada en el proceso de génesis tumoral, así como en la evolución del cáncer. Se cree que aproximadamente el $20 \%$ de los cánceres está precedido de procesos inflamatorios crónicos; tal es el caso del carcinoma hepatocelular precedido por la hepatitis, el cáncer de colon por la enfermedad inflamatoria del intestino y el cáncer gástrico por la infección con Helicobacter pylori. Sin embargo, la inflamación no solo se presenta como antecesora del cáncer, sino también como una consecuencia del crecimiento mismo del tumor, proceso que produce factores reguladores, recluta células de la respuesta inmunitaria y favorece la producción de citocinas proinflamatorias alterando, así, el microambiente tumoral, lo cual promueve el crecimiento y la metástasis de los tumores (Francescone, et al., 2014). Estos hechos llevan a pensar que el control de la inflamación intratumoral es, sin duda, uno de los mecanismos que favorece la regresión tumoral y permite la activación de una respuesta inmunitaria efectiva.

\section{Los productos naturales como alternativa terapéutica contra el cáncer}

Las plantas son una fuente inagotable de productos naturales con actividad biológica útil para la humanidad debido a su gran diversidad de especies y metabolitos, así como a su potencial para sintetizar un sinnúmero de moléculas complejas difíciles de reproducir en el laboratorio (Mondal, et al., 2012). Del casi millón de productos naturales, aproximadamente el $25 \%$ es biológicamente activo; de ellos, cerca del $60 \%$ proviene de plantas (Newman \& Cragg, 2016). Las plantas son útiles no solo por la posibilidad de encontrar en ellas metabolitos activos que puedan utilizarse en forma aislada, sino también como fuente de nuevas medicinas (denominadas actualmente como drogas botánicas) (Gertsch, 2011; Schmidt, et al., 2007).

Las drogas botánicas son mezclas de metabolitos obtenidos a partir de una o varias plantas con actividad biológica establecida que, además, se han caracterizado químicamente, con el fin de conocer los metabolitos presentes en la mezcla (Zhu, et al., 2014). Con las nuevas tecnologías, el desarrollo de la medicina herbal se ha modernizado enormemente, y hoy se lleva a cabo un trabajo riguroso que conjuga la caracterización química y la evaluación biológica de las mezclas, con el fin de obtener mezclas estandarizadas y valoradas biológicamente (Tilton, et al., 2010). Son diversos los estudios en los que se reporta el desarrollo de drogas botánicas para diferentes enfermedades, entre ellas, la enfermedad inflamatoria del intestino (Algieri, et al., 2015), y la activación de la respuesta inmunitaria antiviral (Wang, et al., 2013), así como ayuda en el tratamiento del paciente con cáncer (Diwanay, et al., 2004). La Federal Drug Administration (FDA) de los Estados Unidos ha aprobado ya algunas drogas botánicas (Lei, et al., 2014), aunque son muy pocas teniendo en cuenta el inmenso potencial de la biodiversidad en la producción de nuevos medicamentos.

Las drogas botánicas presentan ventajas frente a las moléculas aisladas, pues actúan en diferentes blancos moleculares, lo cual es importante para combatir la mayoría de las enfermedades cuya naturaleza responde a múltiples factores. La fitoterapia con drogas botánicas se basa en la acción combinada de una mezcla de constituyentes y exhibe efectos farmacológicos producto de la interacción sinérgica 
o antagónica de muchos de los fitoquímicos presentes en la mezcla. Las razones de estas interacciones desde el punto de vista mecánico son la biodisponibilidad, la interferencia con procesos de transporte celular, la activación de profármaco o la desactivación de compuestos activos y su conversión en metabolitos inactivos, la acción de patrones sinérgicos en diferentes puntos de la misma cascada de señalización o la inhibición de la unión a diferentes proteínas blanco, entre otras. Las tecnologías "ómicas" y la biología de sistemas podrían facilitar el estudio de esta multiplicidad de efectos en las mezclas herbales (Efferth \& Koch, 2011).

\section{Anamú y dividivi, dos plantas colombianas con enormes potenciales antitumorales}

La búsqueda de plantas con actividad antitumoral llevada a cabo en nuestro grupo de investigación en los últimos 14 años se basa en el conocimiento tradicional y la esperanza de que los avances que se logren beneficien a la comunidad. El anamú (Petiveria alliacea Linne Phytolaccaceae) se encuentra ampliamente distribuido en la zona andina del país, entre los 700 y los $1.500 \mathrm{msnm}$. El dividivi (Caesalpinia spinosa (Molina) Kuntze), por su parte, esta principalmente presente en Boyacá, en la zona del alto Ricaurte, entre los 1.600 y $2.900 \mathrm{msnm}$. El conocimiento etnofarmacológico de estas plantas no hace parte de esta revisión, sin embargo, vale la pena resaltar que es a través de él que se ha podido inferir que la marcada actividad antioxidante del dividivi puede participar en la regulación de la producción de las ERO dentro y fuera del tumor, lo cual le conferiría un gran potencial antitumoral. Por otra parte, la actividad hipoglucémica del anamú permite pensar que la actividad antitumoral clásicamente atribuida a esta planta se debe a su capacidad de regular la disponibilidad de la glucosa en las células tumorales.

En este contexto, la hipótesis de trabajo de nuestro grupo de investigación en la búsqueda de la actividad antitumoral de estas plantas, se ha basado en el supuesto que los extractos complejos de plantas actuarían directamente sobre la célula tumoral regulando, entre otros, el metabolismo energético para reducir el crecimiento tumoral e, incluso, inducir la muerte de las células, lo que, en consecuencia, activaría la respuesta inmunitaria adaptativa actuando como una vacuna in situ. Esta multiplicidad de funciones de la fitoterapia podría explicar los beneficios observados a lo largo de los años y abriría nuevos interrogantes acerca de la complejidad de las enfermedades crónicas como el cáncer. Esta hipótesis se ha demostrado parcialmente, y en estos próximos años esperamos confirmar nuestros hallazgos y aplicar los resultados al desarrollo de fitomedicamentos efectivos para el tratamiento del cáncer.

\section{Anamú (Petiveria alliacea) como modulador del metabolismo energético de las células tumorales}

El anamú, Petiveria alliacea Linne (Phytolaccaceae), es una hierba perenne, ampliamente utilizada por la medicina tradicional en el Caribe, y en Centroamérica y Suramérica. La infusión de las hojas o de las raíces se conoce por su actividad antiespasmódica, antireumática y antiinflamatoria sistémica, así como antiinflamatorio bucal, como analgésico, y contra la cistitis, el dolor de cabeza, la polineuralgia (beriberi) y como diurético, entre otras; Luz, et al., 2016). Más específicamente, la infusión acuosa se ha utilizado en el tratamiento de la leucemia y el cáncer de seno (García-Barriga, 1974). En cuanto a su actividad sobre el metabolismo, el conocimiento tradicional le atribuye propiedades hipoglucémicas, pero los datos son contradictorios, ya que se ha evidenciado que el tratamiento con infusión de anamú aumenta la glucemia en forma significativa durante las primeras semanas de consumo (García-González, et al., 2006).

Los extractos de plantas pueden obtenerse de múltiples formas. Una de ellas es la purificación biodirigida, la cual permite determinar la o las sustancias responsables de la actividad biológica mediante procesos simultáneos de separación y ensayo, por lo cual se seleccionó para la obtención del extracto de anamú (Cifuentes, 2010). Con esta tecnología se identificaron varias fracciones del anamú que presentaron actividades biológicas complementarias. Tres de las fracciones concentradas a partir del extracto obtenido en acetato de etilo, denominadas S1 a S3, demostraron actividad citotóxica en líneas de células leucémicas (K562 y NB4) e indujeron apoptosis por la vía mitocondrial, dado que se observó una despolarización temprana e irreversible de la membrana mitocondrial, fragmentación del ADN y modulación intracelular de la HSP70, conocida como una proteína de estrés intracelular (Cifuentes, et al., 2011).

El rendimiento en la obtención de las fracciones con mayor actividad biológica ha sido bajo, lo cual ha impedido optimizar el proceso para obtener un producto con potencial farmacéutico y supuso la necesidad de mejorar el rendimiento. Para ello, se utilizó solamente la fracción completa obtenida en acetato de etilo y se evaluó la actividad en modelos biológi$\cos$. En el análisis mediante polimorfismos en la longitud de fragmentos amplificados de ADN complementario (cDNAAFLP) se observó que esta fracción compleja de anamú, también con actividad citotóxica, indujo una expresión diferencial de genes en células K562. En esta fracción se identificaron algunos de los compuestos presentes en las 'subfracciones' obtenidas previamente (Santander \& Urueña, 2009).

La fracción que se pudo obtener en mayores cantidades fue caracterizada química y biológicamente para confirmar algunos de los hallazgos previos. Se encontró que presentó actividad citotóxica en líneas celulares tumorales de melanoma de ratón y humanas, conservando la citotoxicidad frente a las líneas de células leucémicas. Además, indujo cambios morfológicos, posiblemente por su acción en los filamentos de actina, lo cual se observó principalmente en las líneas adherentes, acompañado de una detención en la fase G2 del ciclo celular (Urueña, et al., 2008). Este último efecto había sido reportado previamente para algunos de los compuestos identificados en el extracto alcohólico del anamú (Rösner, et al., 2001). 
El análisis proteómico en las células tumorales tratadas con la fracción arrojó un perfil complejo en respuesta al tratamiento, el cual afectó las proteínas que participan en la proliferación celular y en el metabolismo energético. Ello sugiere que el extracto de anamú utiliza múltiples mecanismos biológicos para regular el crecimiento tumoral (Urueña, et al., 2008). La actividad de esta fracción se verificó en diversas líneas celulares, particularmente de cáncer de seno, con el objeto de evaluar posteriormente su actividad in vivo en modelos animales. Se observó que en la línea de adenocarcinoma mamario de ratón 4T1 el extracto indujo apoptosis con activación de la caspasa 3, fragmentación del ADN sin despolarización de la membrana mitocondrial y disminución de la capacidad de clonación de las células tumorales.

Los cambios observados previamente en la expresión de las enzimas glucolíticas, se vieron reflejados en este modelo con una disminución en la captación de glucosa y en la producción de lactato. En el modelo in vivo el extracto disminuyó la evolución de tumores mamarios de ratón después del trasplante ortotópico de células 4T1 marcadas con la proteína verde fluorescente, lo que confirmó su actividad antitumoral en un modelo de ratón con cáncer de seno altamente agresivo (Hernández, et al., 2014).

Más recientemente, se ha observado que la actividad del anamú es específica de las células tumorales, en las cuales se encontró una reducción en la expresión de la enzima $\beta$-F1-ATPasa, en la activación del flujo glucolítico, en la concentración de ATP intracelular y en la respiración mitocondrial, con un bajo consumo de oxígeno. Como consecuencia de esta catástrofe energética inducida por el extracto, se observó una disminución de la proliferación celular tanto en los cultivos convencionales en dos dimensiones (2D), como en las esferas cultivadas en tres dimensiones (3D) y enriquecidas en células madre tumorales. En los modelos in vivo en ratones con trasplante ortotópico de la línea celular de adenocarcinoma mamario de ratón TS/A, se observó una disminución en el tumor primario y una mayor supervivencia de los animales, corroborando así el potencial de este extracto en el tratamiento del cáncer de seno (Hernández, et al., 2017).

\section{Compuestos aislados de Petiveria alliacea y su participación en la actividad citotóxica}

Recientemente se publicaron los principales compuestos presentes en el anamú, así como su actividad biológica, (Luz, et al., 2016), por lo que no se discutirá en esta revisión. El trabajo del grupo se centró en la búsqueda de los metabolitos que se encontraban presentes en la fracción con actividad biológica, con el fin de utilizarlos como marcadores para su estandarización. Para ello se realizó inicialmente la derivatización de la fracción completa $\mathrm{y}$ se analizó por espectrometría de masas acoplada a cromatografía de gases (GC-MS). Los espectros de masas de cada uno de los compuestos detectados se analizaron empleando la base de datos MSD Chemstation y NIST MS2011. En la Figura 2 se muestra el espectro de masas obtenido para la fracción total acetilada, señalando los compuestos identificados: (1) benzaldehido, (2) leridol, (3) petiveral, (4) petiveral-4-etil, (5) bencilmetildisulfuro, (6) pinitol, (7) dibencil disulfuro (DDS) y (8) dibencil trisulfuro (DTS), compuestos previamente reportados en la especie por otros autores (Adesogan, 1974; Ayedoun, et al., 1998; De Sousa, et al., 1990; Suárez \& Delle Monache, 1992). El DDS y el DTS ya se han encontrado implicados en la actividad en el citoesqueleto celular (Rösner, et al., 2001).

Una vez identificados los principales compuestos, se estableció la huella cromatográfica de la fracción de anamú adicionando un estándar de DDS y DTS, como se muestra en la Figura 3. La fracción estandarizada se denominó "Esperanza".

Con el fin de evaluar la participación de cada uno de los compuestos en la actividad citotóxica de la fracción, se aislaron algunos de los compuestos. En la Tabla 1 se presentan los compuestos y la actividad citotóxica en las líneas de células tumorales 4T1 de cáncer de seno de ratón y MCF7 de cáncer de seno humano. Entre los compuestos aislados se encontró un caroteno, el dibecil disulfuro, una mezcla de esteroles, el $3 \beta$-isoarborinol, y un ácido graso insaturado (ácido octadeca-7,10,13-trienoico) que está presente en gran cantidad en el extracto.

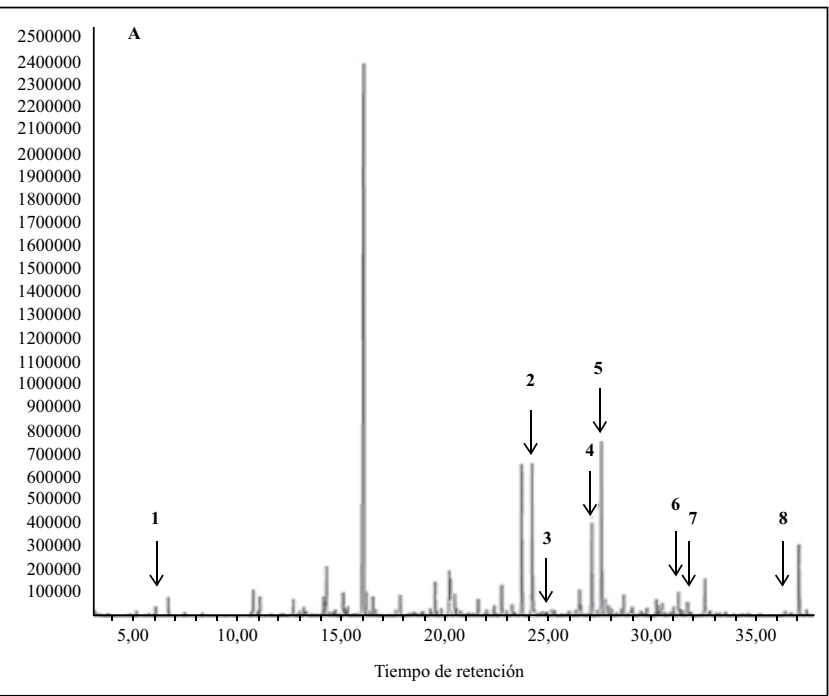

Figura 2. El recuento total de iones (total ion cromathogram, TIC) obtenido por espectrometría de masas acoplada a cromatografía de gases (GC-MS) para la fracción de $P$. alliacea derivatizada con anhídrido acético. La porción lipofílica de dicha fracción se analizada por GC-MS empleando una columna HP-5MS en un equipo Agilent GC 6850II con un detector de masas Agilent 5975CVL. Las flechas indican los siguientes compuestos detectados: (1) benzaldehido, (2) leridol, (3) petiveral, (4) petiveral-4-etil, (5) bencilmetildisulfuro, (6) pinitol, (7) dibencil disulfuro (DDS) y (8) dibencil trisulfuro (DTS). Los datos se compararon con las bases de espectros MSD (Mass Selective Detector) Chemstation y NIST MS 2011. 


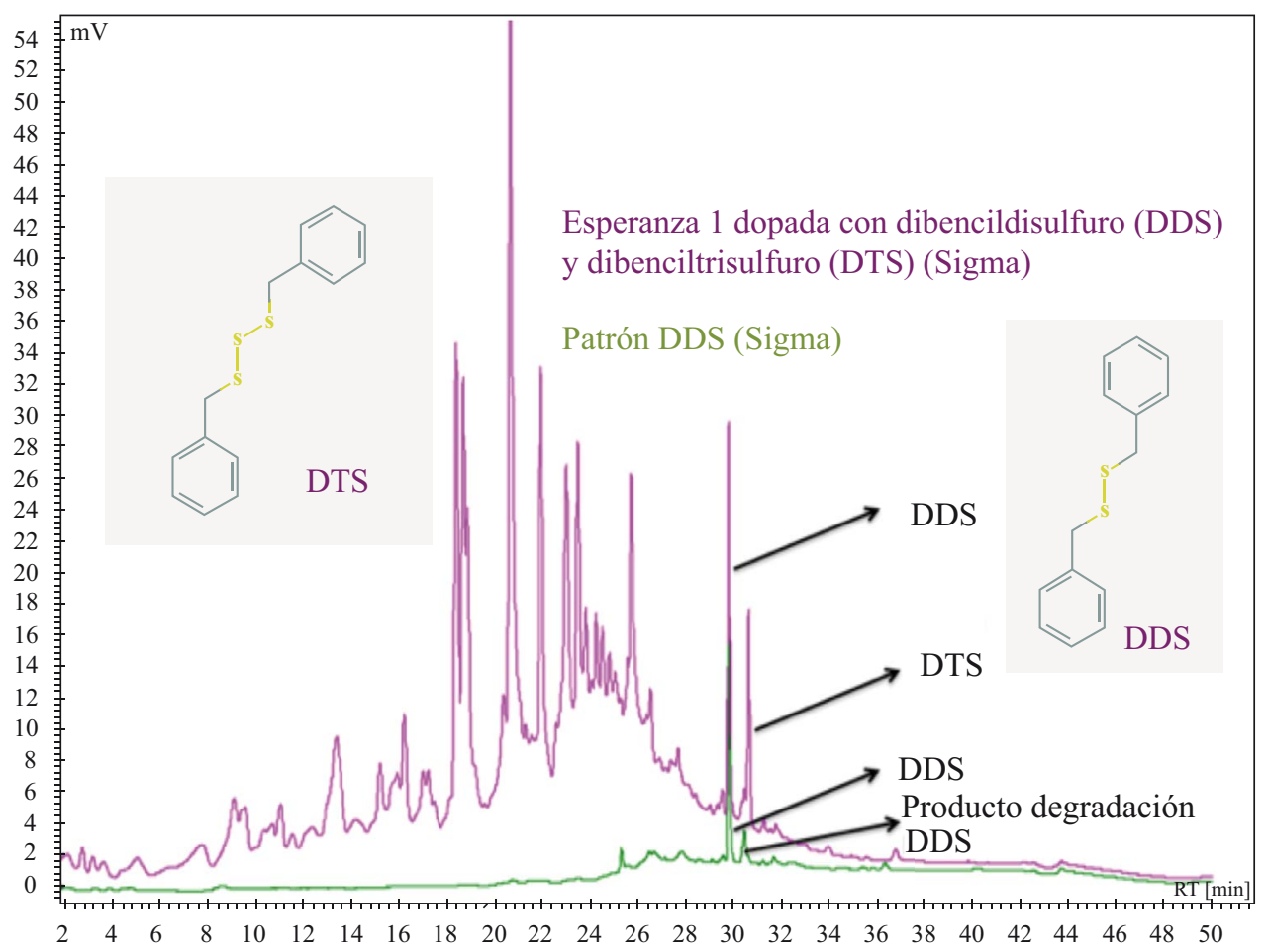

Figura 3. Huella dactilar cromatográfica de la fracción $(3 \mu \mathrm{g})$ "Esperanza I" adicionada con los patrones de DDS y DTS (perfil violeta). La fracción se analizó mediante HPLC a $254 \mathrm{~nm}$ en una columna C18 de 1,6 x $150 \mathrm{~mm}$, gradiente de la fase móvil H2O - ACN t 0-1 90: 10; t 25-36 0:100; t 50 90:10. Flujo de 0,4 ml/min en un equipo Jasco PU2089plus con detector UV2070. Bajo las mismas condiciones analíticas se analizó el patrón de DDS (perfil verde).

Tabla 1. Compuestos aislados y caracterizados a partir de un extracto de Anamú con actividad citotóxica sobre líneas de cáncer de seno murino (4T1) y humano (MCF-7) por MTT.

\begin{tabular}{|c|c|c|c|c|}
\hline \multirow[t]{2}{*}{ Compuesto } & \multirow[t]{2}{*}{ Nombre } & \multirow[t]{2}{*}{ Nombre Iupac } & \multicolumn{2}{|c|}{ Actividad Citotóxica CI50 (mg/ml) } \\
\hline & & & $4 \mathrm{T1}$ & MCF-7 \\
\hline & UJAV-A-2 & Caroteno & $110,8 \pm 4,01$ & $66,87 \pm 2,62$ \\
\hline & UJAV-ScSi 2-2 & Dibecildisulfuro & $1,262 \pm 4,63$ & $4,019 \pm 4,85$ \\
\hline & UJAV-19 & $\begin{array}{c}\text { Mezcla esteroles } \\
\text { (stigmasterol y } \\
\text { sitosterol) }\end{array}$ & $>250$ & $189,0 \pm 3,14$ \\
\hline & UJAV-A9-4 & $3 \beta$-isoarborinol & $>250$ & $7,206 \pm 3,22$ \\
\hline & UJAV-AN4-4 & $\begin{array}{c}\text { Ácido graso } \\
\text { insaturado }\end{array}$ & $86,59 \pm 3,92$ & $58,24 \pm 1,78$ \\
\hline
\end{tabular}




\section{Efecto inmunomodulador del anamú}

$\mathrm{Al}$ igual que muchos otros compuestos obtenidos a partir de plantas, el anamú se ha reportado como un inmunomodulador (Lopes-Martins, et al., 2002; Murugananthan, et al., 2013; Queiroz, et al., 2000; Williams, et al., 1997). Se entiende por inmunomodulación la actividad que se ejerce sobre los componentes del sistema inmunitario, la cual puede inducir cambios en el número de células de la respuesta inmunitaria en los diferentes compartimentos tisulares, o activándolas, así como alteraciones en el perfil de las citocinas, cuya función es permitir la comunicación intercelular. La célula dendrítica es una de las principales células que participan en la presentación de antígenos y en la generación de la respuesta inmunitaria adaptativa, es decir la respuesta de los linfocitos T específicos de antígeno, y por ello se evaluó la actividad del anamú en ellas. Teniendo en mente que el uso tradicional del anamú se hace en infusión, y que estas preparaciones están enriquecidas por metabolitos primarios, entre los cuales puede haber polisacáridos que son potenciales activadores de las células dendríticas (Amon, et al., 2014; Ferreira, et al., 2015), se comparó la actividad inducida por los extractos acuosos y orgánicos de la planta sobre dichas células. Los resultados mostraron que los extractos acuosos indujeron cambios morfológicos relacionados con la activación celular, como la formación de dendritas, así como la expresión de las CD86, pero solo en un pequeño porcentaje de la población total. El CD86 es un marcador de activación de las células dendríticas, sin embargo, la expresión parcial indica que su activación fue incompleta. Se encontró, además, un perfil de citocinas que participan en la respuesta inmunosupresora, como son las interleucinas (IL) IL-1 $\alpha$, IL-6, IL-8, IL-10, así como citocinas proinflamatorias como la IL-12p70 y el TNF- $\alpha$, pero estas últimas en concentraciones menores que el lipopolisacárido conocido por activar esta población. Se observó, además, el incremento de la expresión de NF- $\mathrm{KB}$ y la regulación negativa de la expresión de TGF- $\beta$. Estos resultados sugieren que la fracción acuosa puede tener un papel en la supresión de la respuesta inflamatoria y, probablemente, en la inducción de tolerancia a través de la activación parcial de las células dendríticas, lo cual debería evaluarse en detalle en el contexto de la inmunidad antitumoral. Cabe resaltar que estos efectos sobre la célula dendrítica no se observaron con la fracción orgánica (Santander, et al., 2012).

\section{El dividivi (Caesalpinia spinosa) como compuesto antitumoral $\mathrm{e}$ inmunoestimulante}

Antecedentes y caracterización química. Caesalpinia spinosa (Molina) Kuntze, comúnmente denominada dividivi o dividivi, es un arbusto al que se le atribuyen propiedades antimicrobianas (Aguilar-Gálvez, et al., 2014), antitumorales (Aguilar-Gálvez, et al., 2014; El-Nashar, et al., 2015), y es conocida por su alta capacidad antioxidante (Chambi, et al., 2013; Skowyra, et al., 2014). En América Latina, particularmente en Perú, se ha estudiado ampliamente y se explota como fuente de taninos para el tratamiento de los cueros y la producción de derivados utilizados en la industria química. En Colombia se da en forma silvestre y no ha recibido la atención necesaria a pesar de su potencial agroindustrial. La actividad biológica de la planta se ha atribuido a la presencia de estos taninos hidrolizables (derivados del ácido gálico) en los frutos, los cuales se caracterizan por tener anillos fenólicos, que se encuentran frecuentemente en plantas vasculares.

Clifford, et al. (2007) determinaron la presencia de al menos 45 compuestos fenólicos derivados del ácido caféico y del ácido gálico mediante un análisis de cromatografía líquida acoplada a espectrometría de masas. La extracción llevada a cabo a partir de frutos de dividivi recolectados de arbustos silvestres en la provincia de Ricaurte en Boyacá, nos ha permitido confirmar en una primera aproximación fitoquímica la presencia de galotaninos y derivados del ácido gálico, así como de pentagaloil glucosa, entre otros metabolitos (Pombo, 2008). El extracto obtenido, el cual denominamos P2Et, se ha podido producir a escala piloto y en él se han identificado los metabolitos presentes; se aislaron, asimismo, por lo menos diez compuestos para su estandarización y se determinó su actividad biológica en diferentes líneas celulares (Sandoval, et al., 2016). En la Figura 4 se muestra el perfil cromatográfico de diferentes lotes de P2Et en los cuales se identificaron los metabolitos marcadores: ácido gálico (AG), galato de metilo (MG) y galato de etil (EG); en ellos se analizó la variación de la concentración en cada lote calculando el área bajo la curva, y se determinó la variación de la actividad citotóxica en las células tumorales de ratón $4 \mathrm{~T} 1$, la cual presentó la concentración inhibitoria requerida para matar el $50 \%$ de las células $\left(\mathrm{IC}_{50}\right)$ entre 25 y $37(\mathrm{ug} / \mathrm{ml})$ en los diferentes lotes (datos de nuestro laboratorio). En la Tabla 2 se presentan algunos de los metabolitos aislados a partir de la fracción P2Et y su participación en la actividad citotóxica

\section{Actividad antitumoral del P2Et mediante la inducción de la respuesta inmunitaria}

Los estudios realizados con el extracto P2Et han demostrado que induce apoptosis en líneas de células humanas y de ratón con cáncer de seno y leucemias mediante la despolarización de la mitocondria, la activación de la caspasa 3 , la condensación de la cromatina y la disminución de la capacidad clonogénica en células K562 y 4T1. Además, cuando se usó en conjunto con fármacos quimioterapéuticos como la doxorubicina en concentraciones no letales, se observó una reducción de la $\mathrm{IC}_{50}$, lo que representa un aumento en la actividad antitumoral neta del medicamento, la cual se traduciría en la posibilidad de utilizar menos doxorubicina cuando se administre en asocio con el extracto de dividivi (Castañeda, $\boldsymbol{e t}$ al., 2012; Pombo, 2008; Urueña, et al., 2013)

En el modelo in vivo, además, el extracto redujo el tumor primario de ratones $\mathrm{BALB} / \mathrm{c}$ con trasplante ortotópico de células 4T1 de cáncer de seno y disminuyó las metástasis, 
principalmente en el bazo. Por otra parte, se observó una reducción de la reacción leucemoide, así como de los niveles séricos de IL-6, ambos factores relacionados con un peor pronóstico de la enfermedad, lo que sugiere que el extracto no solamente actúa sobre el tumor primario, sino que también reduce la migración celular a órganos distantes, es decir, implica su actividad en el microambiente tumoral (Urueña, et al., 2013).

La disminución de las metástasis puede deberse a varios factores, entre ellos una actividad sobre las células madre tumorales o la activación de la respuesta inmunitaria, la cual puede controlar la población tumoral que ha migrado a órganos distantes. Con el fin de evaluar la primera hipótesis, se evaluó la actividad citotóxica del P2Et después de múltiples pasajes in vivo en células tumorales que presentaban diferentes perfiles de resistencia a drogas, sea por la sobreexpresión de bombas de resistencia a drogas de tipo Pgp o por enriquecimiento de la población de células madre tumorales. Se observó que, in vitro, el P2Et es citotóxico tanto en las líneas Pgp+ como en las Pgp-, y que, además, pudo modular la actividad de las bombas de resistencia, principalmente con sus compuestos más hidrofóbicos, lo que conlleva un aumento de la sensibilidad de las células resistentes a fármacos como la doxorubicina cuando estas se tratan previamente con el P2Et en cultivos 2D y 3D. Es interesante que los resultados obtenidos in vitro no siempre concordaron con lo observado in vivo. De hecho, cuando se evaluó el efecto del P2Et en células TS/A CD $44^{+} \mathrm{CD} 24^{\text {low }}$, no se observó sinergia con la doxorubicina, sin embargo, cuando el tratamiento se aplicó in vivo, se observó claramente que el tratamiento conjunto de P2Et con doxorubicina resultaba más eficaz en términos de tamaño tumoral y supervivencia de los animales con trasplante ortotópico con estas células (Sandoval, et al., 2016). Estos resultados sugieren que el P2Et puede contrarrestar la resistencia a las drogas, al menos cuando está mediada por la expresión de bombas de resistencia, dado que hallazgos más recientes han demostrado que el P2Et no tiene actividad contra las células tumorales que expresan la enzima ALDH, la cual constituye un marcador relevante de las células madres tumorales y que participa activamente en la detoxificación intracelular (Xu, et al., 2015). Por el contrario, estas células pueden eliminarse cuando se activa la respuesta inmunitaria (artículo en preparación), lo que evidencia, una vez más, que el tratamiento antitumoral debe aplicarse en múltiples niveles para poder dar cuenta de la heterogeneidad celular presente en los tumores in vivo.

La segunda hipótesis en torno a la activación de la respuesta inmunitaria se estudió inicialmente en el modelo de cáncer de seno con células 4T1. Se observó que el tratamiento de las células tumorales con el extracto P2Et indujo la expresión de marcadores de muerte celular inmunogénica, conocidos por su papel en la activación de las células dendríticas (Krysko, et al., 2012), tales como la expresión de calreticulina en la membrana plasmática, la movilización extranuclear de la proteína HMGB-1 y la liberación de ATP. Cuando los animales se vacunaron con células 4T1 tratadas in vitro con P2Et, se controló mejor el desarrollo del tumor y se detectaron directamente ex vivo linfocitos T CD4 y CD8 de larga vida, multifuncionales,
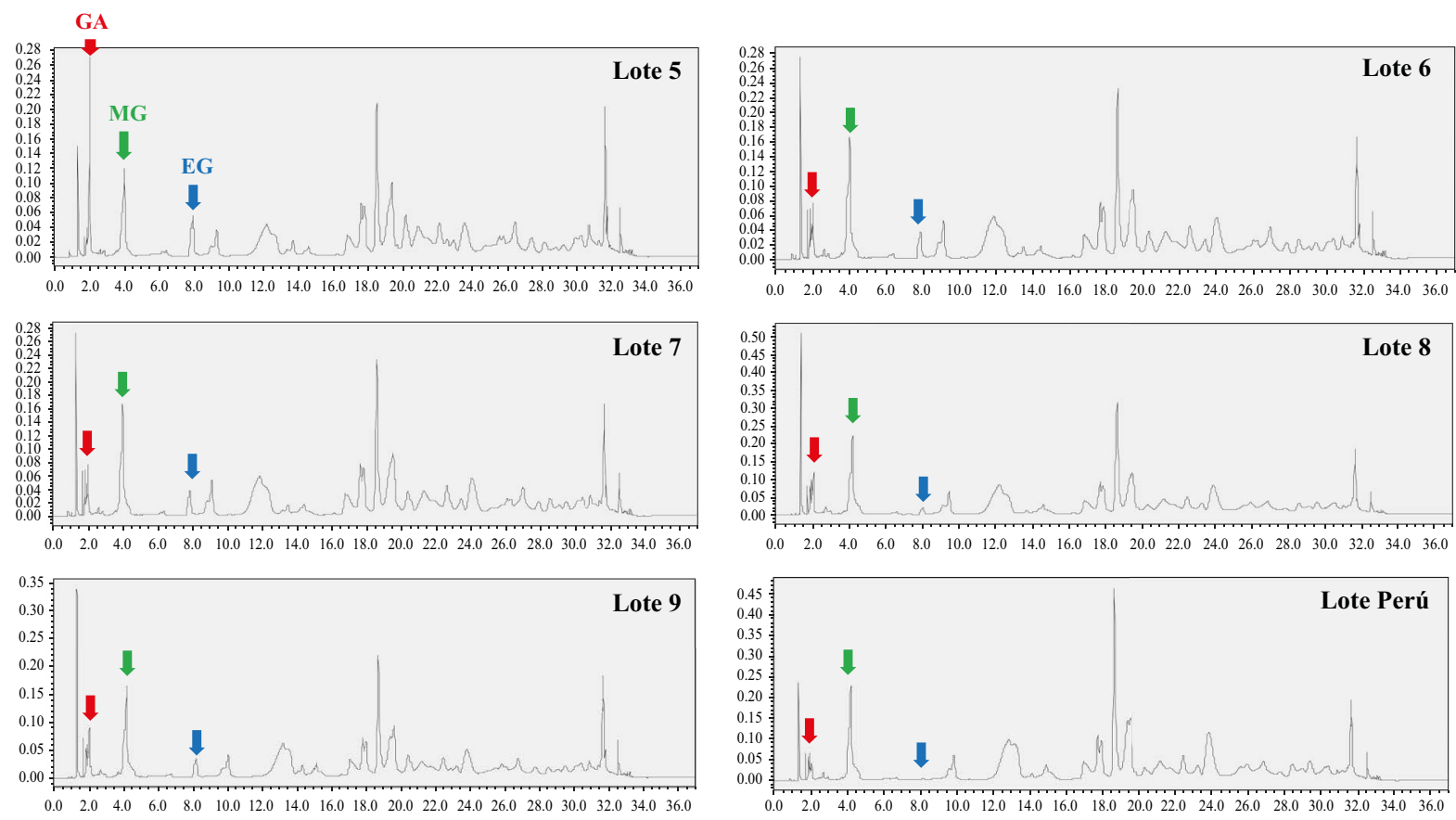

Figura 4. Perfil cromatográfico de diferentes lotes de P2Et. Se identifican los metabolitos marcadores del extracto P2Et: ácido gálico (AG), metil galato $(\mathrm{MG})$ y etil galato $(\mathrm{EG})$ 
Tabla 2. Compuestos aislados del Dividivi y actividad citotóxica medida por la técnica de MTT sobre células tumorales de cáncer de seno murino (4T1) y humano (MCF7).

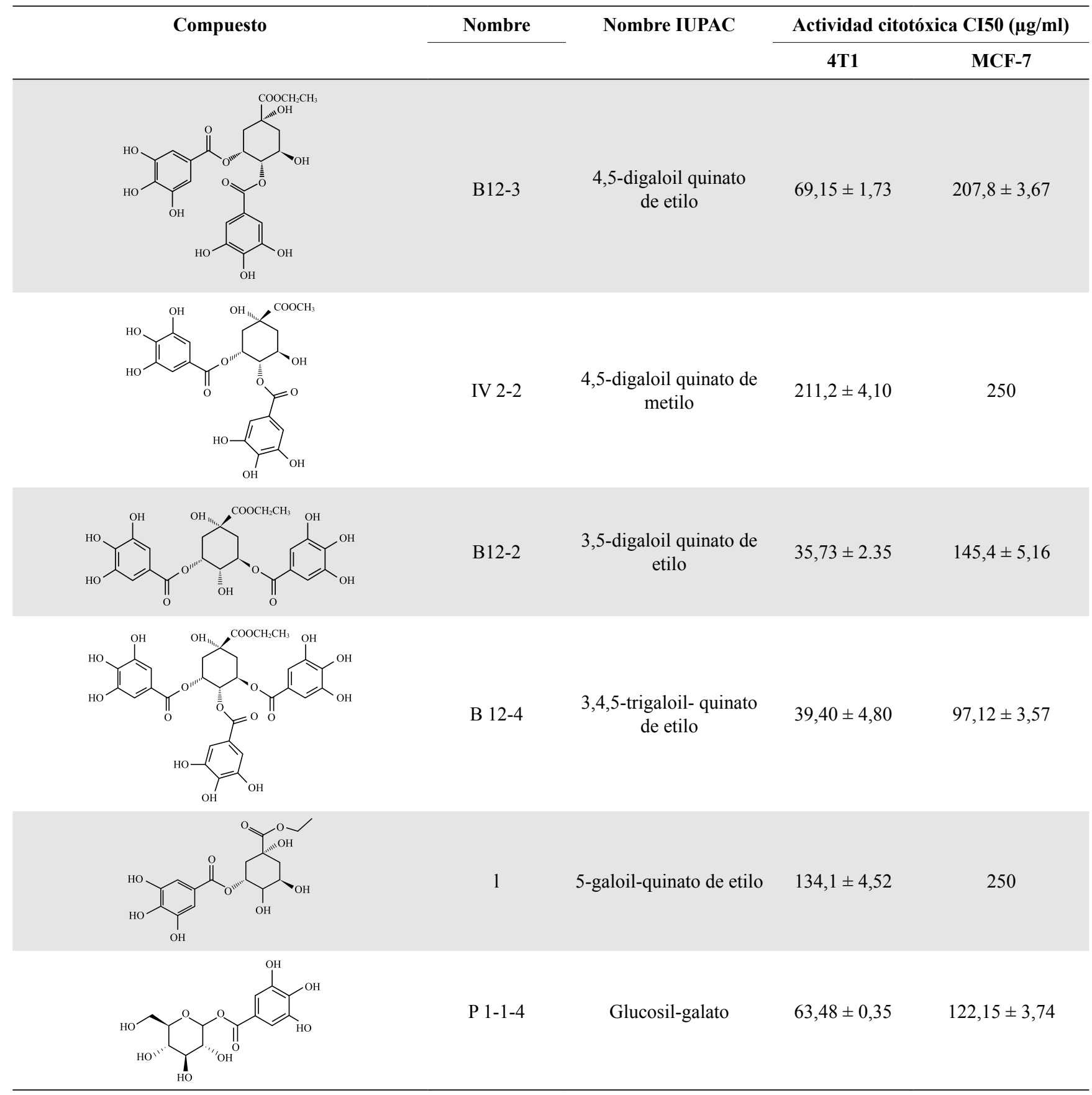

y productores de citocinas como las IL-2, IFN- $\gamma$ y TNF- $\alpha$. Además, esta población responde a la estimulación in vitro con un extracto de tumor, lo que produjo IL-2, TNF- $\alpha$, IL-4, IL-5, e IFN- $\gamma$ y demostró la generación de células de memoria específicas del antígeno, las cuales se han activado suficientemente como para llegar a un estado de diferenciación que les permita producir citocinas de tipo Th2 (Urueña, et al., 2013). Estos hallazgos fueron muy interesantes para la comprensión de la actividad del extracto y nos han llevado a plantear nuevas hipótesis. Es posible que el extracto no solo actúe sobre el tumor sino también sobre las células presentadoras de antígeno, lo que permite la activación de la respuesta inmunitaria, con un patrón parcialmente inmunomodulador al encontrar citocinas del tipo de las Th2, las cuales podrían modular también el proceso inflamatorio deletéreo por su papel antiinflamatorio.

En el modelo tumoral con células 4T1 es muy difícil determinar si realmente hay activación de la respuesta 
específica de antígeno, dado que no hay antígenos claramente identificados. Por esta razón, en colaboración con Pedro Romero, del Instituto Ludwig de Lausana, se evaluó el efecto del extracto P2Et en el modelo de melanoma de ratón con células B16 en animales C57BL/6. En este modelo, se han identificado varios antígenos tumorales que permiten detectar más fácilmente la población de linfocitos $\mathrm{T}$ específicos de antígeno. Los resultados obtenidos demostraron que el tratamiento de las células B16 con el P2Et indujo activación de las caspasas 3 y 9, movilización del citocromo c al citoplasma y externalización de la fosfatidilserina como marcador de apoptosis. Además, indujo autofagia, la cual se ha vinculado recientemente como un evento necesario en la activación de la respuesta inmunitaria de las células tumorales (Martins, et al., 2014) y la expresión de marcadores de muerte celular inmunogénica, tal como se observó en el modelo de cáncer de seno. Además, se encontraron células CD8 dirigidas contra el antígeno de melanoma (Trp-2) productoras de IFN- $\gamma$, lo que refleja un proceso de sensibilización cruzada que permitió la activación de linfocitos T específicos. Por otra parte, se encontró que el efecto protector del P2Et, al menos en este modelo, queda abolido en ratones inmunodeficientes en los cuales se pierde parcialmente la actividad antitumoral, lo cual se corroboró al hacer experimentos de depleción de linfocitos T CD4 y CD8 en animales silvestres, e indica que la actividad antitumoral del P2Et es altamente dependiente de la respuesta inmunitaria adaptativa (Gómez-Cadena, et al., 2016).

\section{Actividad de los extractos de anamú y dividivi en células tumorales humanas primarias}

Los extractos de anamú y dividivi también presentaron actividad en células tumorales primarias humanas obtenidas de pacientes con cáncer de seno y leucemia. En las de pacientes con cáncer de seno cultivadas en 3D para enriquecerlas en células madres tumorales fueron sensibles al P2Et y al anamú y dicha sensibilidad al parecer aumentó en el cultivo adicionado con doxorubicina (publicación en preparación).

Por el contrario, las células obtenidas de pacientes con leucemia linfoide aguda o leucemia mieloide aguda se han mostrado menos sensibles al P2Et y han presentado una mayor sensibilidad al extracto de anamú. Además, el tratamiento de los blastos con los dos extractos combinados y los fármacos de elección, aumentó la sensibilidad a la muerte incluso en células tumorales que en algunos casos no responden a las terapias convencionales (publicación en preparación). Estos datos, aunque preliminares, evidencian que, por lo menos in vitro, los extractos de anamú y dividivi son capaces de actuar en los tumores primarios humanos mejorando la respuesta a la quimioterapia. Queda por comprobarse cuál es su papel en la modulación del microambiente tumoral y evaluarlo en estudios clínicos para saber si la actividad observada in vitro se encuentra también in vivo, lo cual tendría un impacto importante en la respuesta al tratamiento y, sobre todo, en la supervivencia de los pacientes.

\section{Optimización del P2Et en condiciones de buenas prácticas de manufactura y avances en los análisis preclínicos}

El trabajo realizado hasta el momento se ha orientado a validar el conocimiento científico sobre el uso medicinal de estas plantas y, además, a producir en forma estandarizada un extracto que pueda usarse como fitomedicamento y se ajuste a las normas de la Federal Drug Administration FDA (Estados Unidos), el Instituto Nacional de Vigilancia de Medicamentos y Alimentos - Invima (Colombia) y de la Agência Nacional de Vigilância Sanitária -ANVISA (Brasil). Para la producción de los lotes industriales del extracto en prueba piloto, deben cumplirse las condiciones de buenas prácticas de manufactura (BPM), las cuales se definen como el conjunto de normas operativas destinadas a asegurar la calidad de los medicamentos. En Colombia, las BPM se rigen por la resolución 1160 de 2016 mediante la cual se adoptó oficialmente el manual de las BPM de la Organización Mundial de la Salud (OMS) (serie de informes técnicos número 823 - Informe 32).

La forma farmacéutica sólida del fitomedicamento P2Et en cápsula se produce actualmente en los Laboratorios Labfarve, los cuales fueron nuevamente certificados hasta el año 2021 por el Invima en buenas prácticas de manufactura ajustadas para producción y control de calidad según el informe 32 de la OMS. Además, la producción del P2Et se ajusta a lo dispuesto en el decreto 2266 de 2004, el cual reglamenta la producción de los fitoterapéuticos en Colombia.

Las pruebas de calidad del ingrediente farmacéutico activo del P2Et se hicieron en el material vegetal y ya en dicho ingrediente terminado. Dado que en Colombia la norma (Decreto 2266 de 2004) no establece las pruebas específicas que deben hacerse en los extractos, en el desarrollo del P2Et nuestro grupo se ha guiado por las normas de los organismos regulatorios internacionales con plena homologación en Colombia según el decreto 0162 de 2004: el Formulário de Fitoterápicos Farmacopeia Brasileira de la ANVISA, aquellas para artículos de origen botánico del The United States Pharmacopeia and National Formulary (USP38-NF33), la guía de la FDA Botanical Drug Development Guidance for Industry y la de Quality control methods for herbal materials de la OMS.

Las pruebas de calidad que se deben realizar sobre el ingrediente farmacéutico activo para obtener el certificado de análisis para el material vegetal son el i) certificado de la muestra registrada en el Herbario Nacional Colombiano, ii) identificación de la especie, iii) pruebas de control de calidad (aflatoxinas, metales pesados, pesticidas) y otros contaminantes, iv) reseña botánica de la especie (aspectos de ecología, cultivo, aprovechamiento y sostenibilidad), v) certificación de cultivo y recolección de dividivi en condiciones de buenas prácticas de agricultura en la provincia del Alto Ricaurte, Boyacá, Colombia.

Asimismo, es necesario aportar el i) certificado de análisis, ii) el origen botánico de la fracción P2Et, iii) las 
propiedades organolépticas (apariencia, color, olor, sabor), iv) la identificación por HPLC o CCD, v) el análisis fisicoquímico (porcentaje de humedad, cenizas totales, cenizas insolubles, solventes residuales) y vi) los análisis microbiológicos.

\section{Normalización del ingrediente farmacéutico activo P2Et}

Las agencias regulatorias requieren, además, que la metodología de identificación del ingrediente farmacéutico activo este normalizada, para lo cual se utilizó el documento de la International Conference on Harmonisation (ICH) Validation of Analytical Procedures: Text and methodology Q2. Esta normalización garantiza la consistencia entre los lotes, tal como se explicó anteriormente. Para esta validación se utilizaron siete lotes de P2Et. La técnica analítica de identificación empleada fue la cromatografía líquida de alto rendimiento, la cual está considerada como de categoría I por el Invima fue validada siguiendo los requerimientos establecidos.

\section{Estabilidad y fecha de expiración}

La fecha de expiración del extracto se determinó con base en los resultados del estudio de estabilidad siguiendo los lineamientos del documento técnico del Ministerio de Salud y Protección Social, el cual establece que Colombia se encuentra en la zona IVb, es decir, una zona con acusados cambios climáticos, lo cual define los parámetros a evaluar. Actualmente se están llevando a cabo los estudios de estabilidad acelerada y natural según el documento técnico del Ministerio de Salud y Protección Social, requisito indispensable para registrar y ejecutar el estudio clínico.

\section{Ensayos preclínicos}

Los ensayos preclínicos se requieren para avanzar a la fase clínica. Deben llevarse a cabo observando las buenas prácticas de laboratorio para preparar la documentación de acuerdo a las exigencias de las agencias internacionales. Para el P2Et, estas pruebas se están realizando en Medlab (Brasil), laboratorio que cuenta con instalaciones y procesos certificados y cuenta con autorización para ensayos en animales, los cuales se ejecutan bajo los lineamientos establecidos por la Organización para la Cooperación y el Desarrollo Económicos (OCDE) y el ICH basados en la guía de la FDA Guidance for Industry S9 Nonclinical Evaluation for Anticancer Pharmaceuticals. Las pruebas para garantizar la seguridad del producto antes de administrarlo en humanos son el test de AMES, y los análisis de micronúcleos, de toxicidad oral aguda, de toxicidad oral 'subcrónica' (28 días) y de toxicidad oral crónica (3 y 6 meses). En los análisis de toxicidad oral aguda y subcrónica, se ha demostrado que el extracto es seguro en dosis de $1.000 \mathrm{mg} / \mathrm{Kg}$ de peso administrándolo diariamente durante 28 días, lo que permitirá avanzar en el protocolo clínico de fase I, para así evaluar la seguridad del medicamento en pacientes con cáncer en el 2018.

\section{Agradecimientos}

A la Pontificia Universidad Javeriana, en donde se ha podido realizar toda la investigación reportada, la cual ha sido financiada por la Vicerrectoría de Investigaciones de la Universidad, por Colciencias y el por Sistema General de Regalías del Distrito Capital.

\section{Contribución de los autores}

Claudia Urueña ha llevado a cabo la gran mayoría de los experimentos presentados en esta revisión y ha supervisado la ejecución de técnica y el diseño experimental de los procedimientos que se llevan a cabo en el laboratorio en los últimos 10 años. Susana Fiorentino es la directora del grupo y de la línea de investigación en Quimioprevención y Fitomedicamentos antitumorales desde hace 14 años.

\section{Conflicto de intereses}

Estos resultados hacen parte de una iniciativa empresarial de tipo spin off, denominada Phairilab, en la cual las autoras participan.

\section{Referencias}

Adesogan, E. K. (1974). Trithiolaniacin, a novel trithiolan from Petiveria alliacea. Journal of the Chemical Society, Chemical Communications. 21: 906-907.

Aguilar-Gálvez, A., Noratto, G., Chambi, F., Debaste, F., Campos, D. (2014). Potential of tara (Caesalpinia spinosa) gallotannins and hydrolysates as natural antibacterial compounds. Food chemistry. 156: 301-304.

Algieri, F., Rodríguez-Nogales, A., Rodríguez-Cabezas, M. E., Risco, S., Ocete, M., Gálvez, J. (2015). Botanical drugs as an emerging strategy in inflammatory bowel disease: A review. Mediators of inflammation, 2015.

Almuhaideb, A., Papathanasiou, N., Bomanji, J. (2011). 18F-FDG PET/CT imaging in oncology. Annals of Saudi medicine. 31 (1): 3.

Amon, R., Reuven, E. M., Leviatan Ben-Arye, S., PadlerKaravani, V. (2014). Glycans in immune recognition and response. Carbohydr Res. 389: 115-122. doi:10.1016/j. carres.2014.02.004

Ayedoun, M., Moudachirou, M., Sossou, P., Garneau, F., Gagnon, H., Jean, F.-I. (1998). Volatile constituents of the root oil of Petiveria alliacea L. from Benin. Journal of Essential Oil Research. 10 (6): 645-646.

Cairns, R. A., Harris, I. S., Mak, T. W. (2011). Regulation of cancer cell metabolism. Nat Rev Cancer. 11 (2): 85-95. doi:10.1038/nrc2981

Castañeda, D. M., Pombo, L. M., Urueña, C. P., Hernández, J. F., Fiorentino, S. (2012). A gallotannin-rich fraction from Caesalpinia spinosa (Molina) Kuntze displays cytotoxic activity and raises sensitivity to doxorubicin in a leukemia cell line. BMC complementary and alternative medicine. 12 (1): 38.

Chambi, F., Chirinos, R., Pedreschi, R., Betalleluz-Pallardel, I., Debaste, F., Campos, D. (2013). Antioxidant potential of hydrolyzed polyphenolic extracts from tara (Caesalpinia spinosa) pods. Industrial Crops and Products. 47: 168-175. 
Cifuentes, C. (2010). Proceso biodirigido para la obtencion de fracciones con actividad antitumoral a partir de Petiveria alliacea. (Doctorado), Pontificia Universidad Javeriana, Bogotá.

Cifuentes, M. C., Castañeda, D. M., Urueña, C. P., Fiorentino, S. (2011). A fraction from Petiveria alliacea induces apoptosis via a mitochondria-dependent pathway and regulates HSP70 expression. Universitas Scientiarum. 14 (2): 125-134.

Clifford, M. N., Stoupi, S., Kuhnert, N. (2007). Profiling and characterization by LC-MS $\mathrm{n}$ of the galloylquinic acids of green tea, tara tannin, and tannic acid. Journal of agricultural and food chemistry. 55 (8): 2797-2807.

Colegio, O. R., Chu, N.-Q., Szabo, A. L., Chu, T., Rhebergen, A. M., Jairam, V., ... Phillips, G. M. (2014). Functional polarization of tumour-associated macrophages by tumourderived lactic acid. Nature. 513 (7519): 559.

Cort, A., \& Ozben, T. (2015). Natural Product Modulators to Overcome Multidrug Resistance In Cancer. Nutr Cancer. 67: 1-13. doi:10.1080/01635581.2015.1002624

Courtois-Cox, S., Jones, S., Cichowski, K. (2008). Many roads lead to oncogene-induced senescence. Oncogene. 27 (20): 2801.

Dave, B., Mittal, V., Tan, N. M., Chang, J. C. (2012). Epithelialmesenchymal transition, cancer stem cells and treatment resistance. Breast Cancer Res. 14 (1): 202. doi:10.1186/ ber2938

De Sousa, J. R., Demuner, A. J., Pinheiro, J. A., Breitmaier, E., Cassels, B. K. (1990). Dibenzyl trisulphide and trans-Nmethyl-4-methoxyproline from Petiveria alliacea. Phytochemistry. 29 (11): 3653-3655.

Diwanay, S., Chitre, D., Patwardhan, B. (2004). Immunoprotection by botanical drugs in cancer chemotherapy. Journal of Ethnopharmacology. 90 (1): 49-55.

Efferth, T., \& Koch, E. (2011). Complex interactions between phytochemicals. The multi-target therapeutic concept of phytotherapy. Current drug targets. 12 (1): 122-132.

El-Nashar, H., Eldahshan, O., Singab, A. (2015). The tribe Caesalpinieae (Fabaceae): An updated review on pharmacological aspects. Med Aromat Plants, 4 (215): 21670412.1000215

Ferreira, S. S., Passos, C. P., Madureira, P., Vilanova, M., Coimbra, M. A. (2015). Structure-function relationships of immunostimulatory polysaccharides: A review. Carbohydr Polym. 132: 378-396. doi:10.1016/j.carbpol.2015.05.079

Fischer, K., Hoffmann, P., Voelkl, S., Meidenbauer, N., Ammer, J., Edinger, M., ... Hoves, S. (2007). Inhibitory effect of tumor cell-derived lactic acid on human T cells. Blood. 109 (9): 3812-3819.

Francescone, R., Hou, V., Grivennikov, S. I. (2014). Microbiome, inflammation and cancer. Cancer journal (Sudbury, Mass.). 20 (3): 181.

García-Barriga, H. (1974). Flora medicinal de Colombia: botánica médica. Fecha de consulta: dd-mm-año. Disponible en: poner el URL

García-González, M., Coto Morales, T., Ocampo, R., Pazos, L. (2006). Subchronic and acute preclinic toxicity and some pharmacological effects of the water extract from leaves of Petiveria alliacea (Phytolaccaceae. Revista de biología tropical. 54 (4): 1323-1326.
Gertsch, J. (2011). Botanical drugs, synergy, and network pharmacology: Forth and back to intelligent mixtures. Planta medica. 77 (11): 1086-1098.

Goetze, K., Walenta, S., Ksiazkiewicz, M., Kunz-Schughart, L. A., Mueller-Klieser, W. (2011). Lactate enhances motility of tumor cells and inhibits monocyte migration and cytokine release. International journal of oncology. 39 (2): 453-463.

Gómez-Cadena, A., Urueña, C., Prieto, K., Martínez-Usatorre, A., Donda, A., Barreto, A., ... Fiorentino, S. (2016). Immune-system-dependent anti-tumor activity of a plantderived polyphenol rich fraction in a melanoma mouse model. Cell death \& disease. 7 (6): e2243.

Hernández, J. F., Urueña, C. P., Cifuentes, M. C., Sandoval, T. A., Pombo, L. M., Castañeda, D., ... Fiorentino, S. (2014). A Petiveria alliacea standardized fraction induces breast adenocarcinoma cell death by modulating glycolytic metabolism. J Ethnopharmacol. 153 (3): 641-649. doi:10. 1016/j.jep.2014.03.013

Hernández, J. F., Urueña, C. P., Sandoval, T. A., Cifuentes, M. C., Formentini, L., Cuezva, J. M., Fiorentino, S. (2017). A cytotoxic Petiveria alliacea dry extract induces ATP depletion and decreases $\beta$-F1-ATPase expression in breast cancer cells and promotes survival in tumor-bearing mice. Revista Brasileira de Farmacognosia. 27 (3): 306-314

Husain, Z., Huang, Y., Seth, P., Sukhatme, V. P. (2013). Tumorderived lactate modifies antitumor immune response: Effect on myeloid-derived suppressor cells and NK cells. The Journal of Immunology. 191 (3): 1486-1495.

Illnait Ferrer, J. (2007). Principales referencias etnomédicas sobre el anamú (Petiveria alliacea Linn) y principios activos encontrados en la planta. un acercamiento al tema. Revista CENIC. Ciencias biológicas, 38 (1): 27-30.

Kaplon, J., Zheng, L., Meissl, K., Chaneton, B., Selivanov, V. A., Mackay, G., ... Shlomi, T. (2013). A key role for mitochondrial gatekeeper pyruvate dehydrogenase in oncogeneinduced senescence. Nature. 498 (7452): 109.

Koppenol, W. H., Bounds, P. L., Dang, C. V. (2011). Otto Warburg's contributions to current concepts of cancer metabolism. Nature Reviews Cancer, 11 (5): 325-337.

Krysko, D. V., Garg, A. D., Kaczmarek, A., Krysko, O., Agostinis, P., Vandenabeele, P. (2012). Immunogenic cell death and DAMPs in cancer therapy. Nature Reviews Cancer. 12 (12): 860-875.

Lei, X., Chen, J., Liu, C.-X., Lin, J., Lou, J., Shang, H.-c. (2014). Status and thoughts of Chinese patent medicines seeking approval in the US market. Chinese journal of integrative medicine. 20 (6): 403-408.

Lieberman, B. P., Ploessl, K., Wang, L., Qu, W., Zha, Z., Wise, D. R., ... Kung, H. F. (2011). PET imaging of glutaminolysis in tumors by $18 \mathrm{~F}-(2 \mathrm{~S}, 4 \mathrm{R})$ 4-fluoroglutamine. Journal of nuclear medicine. 52 (12): 1947-1955.

Lopes-Martins, R., Pegoraro, D., Woisky, R., Penna, S., Sertié, J. (2002). The anti-inflammatory and analgesic effects of a crude extract of Petiveria alliacea L.(Phytolaccaceae). Phytomedicine. 9 (3): 245-248.

Luz, D. A., Pinheiro, A. M., Silva, M. L., Monteiro, M. C., Prediger, R. D., Maia, C.S. F., Fontes-Júnior, E.A.(2016). Ethnobotany, phytochemistry and neuropharmacological effects of Petiveria alliacea L.(Phytolaccaceae): A review. Journal of ethnopharmacology. 185: 182-201. 
Margaryan, N. V., Seftor, E. A., Seftor, R. E., Hendrix, M. J. (2017). Targeting the Stem Cell Properties of Adult Breast Cancer Cells: Using Combinatorial Strategies to Overcome Drug Resistance. Current Molecular Biology Reports. (3): 159-164.

Martins, I., Wang, Y., Michaud, M., Ma, Y., Sukkurwala, A., Shen, S., ... Perfettini, J. (2014). Molecular mechanisms of ATP secretion during immunogenic cell death. Cell death and differentiation. 21 (1): 79.

Mondal, S., Bandyopadhyay, S., Ghosh, M. K., Mukhopadhyay, S., Roy, S., Mandal, C. (2012). Natural products: promising resources for cancer drug discovery. Anticancer Agents Med Chem. 12 (1): 49-75.

Murugananthan, G., Mohan, S., Pabbithi, S. C., Debanjan, D. (2013). Immunomodulatory constituents from plant origins: a review of isolated biomolecules. International Journal of Pharmaceutical Sciences and Research. 4 (7): 2459.

Newman, D. J., \& Cragg, G. M. (2016). Natural products as sources of new drugs from 1981 to 2014. Journal of natural products. 79 (3): 629-661.

Pavlova, N. N., \& Thompson, C. B. (2016). The emerging hallmarks of cancer metabolism. Cell metabolism. 23 (1): 27-47.

Plaks, V., Kong, N., Werb, Z. (2015). The cancer stem cell niche: How essential is the niche in regulating stemness of tumor cells? Cell Stem Cell. 16 (3): 225-238. doi:10.1016/j. stem.2015.02.015

Pombo, L. (2008). Valoración de la actividad antitumoral de extractos y fracciones obtenidas de Caesalpinia spinosa Molina Kuntze sobre diferentes líneas celulares tumorales. Bogotá, Colombia: Pontificia Universidad Javeriana, Maestría en Ciencias Biológicas.

Pombo, M. (2008). Las fracciones obtenidas de Caesalpinia spinosa Molina Kuntze, ejercen diferentes efectos biologicos sobre celulas K562. Maestría en Ciencias Biológicas, Pontificia Universidad Javeriana, Bogotá.

Queiroz, M. S., Quadros, M. R., Santos, L. M. (2000). Cytokine profile and natural killer cell activity in Listeria monocytogenes infected mice treated orally with Petiveria alliacea extract. Immunopharmacology and immunotoxicology. 22 (3): 501-518.

Rösner, H., Williams, L., Jung, A., Kraus, W. (2001). Disassembly of microtubules and inhibition of neurite outgrowth, neuroblastoma cell proliferation, and MAP kinase tyrosine dephosphorylation by dibenzyl trisulphide. Biochimica et Biophysica Acta (BBA)-Molecular Cell Research. 1540 (2): 166-177.

Sandoval, T. A., Urueña, C. P., Llano, M., Gómez-Cadena, A., Hernández, J. F., Sequeda, L. G., . . . Fiorentino, S. (2016). Standardized Extract from Caesalpinia spinosa is Cytotoxic Over Cancer Stem Cells and Enhance Anticancer Activity of Doxorubicin. The American Journal of Chinese Medicine. (08): 1693-1717.

Santander, S., \& Urueña, C. (2009). Influencia del tratamiento de Petiveria alliacea en la expresion diferencial de gene en celulas tumorales. Univ. Med. Bogotá. 50 (3): 284-296.
Santander, S. P., Hernández, J. F., Cifuentes B, C., Aoki, M., Moins-Teisserenc, H., \& Fiorentino, S. (2012). Immunomodulatory effects of aqueous and organic fractions from Petiveria alliacea on human dendritic cells. The American journal of Chinese medicine. 40 (04): 833-844.

Schmidt, B. M., Ribnicky, D. M., Lipsky, P. E., Raskin, I. (2007). Revisiting the ancient concept of botanical therapeutics. Nature chemical biology. 3 (7): 360-366.

Skowyra, M., Falguera, V., Gallego, G., Peiró, S., Almajano, M. P. (2014). Antioxidant properties of aqueous and ethanolic extracts of tara (Caesalpinia spinosa) pods in vitro and in model food emulsions. Journal of the Science of Food and Agriculture. 94 (5): 911-918.

Suarez, L. E. C., \& Delle Monache, F. (1992). 6-C-formyl and 6-C-hydroxymethyl flavanones from Petiveria alliacea. Phytochemistry. 31 (7): 2481-2482.

Sullivan, L. B., \& Chandel, N. S. (2014). Mitochondrial reactive oxygen species and cancer. Cancer \& metabolism. 2 (1): 17

Tilton, R., Paiva, A. A., Guan, J.-Q., Marathe, R., Jiang, Z., van Eyndhoven, W., ... Liu, S.-H. (2010). A comprehensive platform for quality control of botanical drugs (PhytomicsQC): A case study of Huangqin Tang (HQT) and PHY906. Chinese medicine. 5 (1): 30.

Urueña, C., Cifuentes, C., Castañeda, D., Arango, A., Kaur, P., Asea, A., Fiorentino, S. (2008). Petiveria alliacea extracts uses multiple mechanisms to inhibit growth of human and mouse tumoral cells. BMC complementary and alternative medicine. 8 (1): 60

Urueña, C., Mancipe, J., Hernandez, J., Castañeda, D., Pombo, L., Gomez, A., ... Fiorentino, S. (2013). Gallotannin-rich Caesalpinia spinosa fraction decreases the primary tumor and factors associated with poor prognosis in a murine breast cancer model. BMC complementary and alternative medicine. 13 (1): 74.

Venneti, S., Dunphy, M. P., Zhang, H., Pitter, K. L., Zanzonico, P., Campos, C., ... Ploessl, K. (2015). Glutamine-based PET imaging facilitates enhanced metabolic evaluation of gliomas in vivo. Science translational medicine, 7 (274): 274ra217-274ra217.

Wang, X., Xu, X., Li, Y., Li, X., Tao, W., Li, B., ... Yang, L. (2013). Systems pharmacology uncovers Janus functions of botanical drugs: Activation of host defense system and inhibition of influenza virus replication. Integrative Biology. 5 (2): 351-371.

Warburg, O. (1956). On respiratory impairment in cancer cells. Science (New York, NY). 124 (3215): 269-270.

Williams, L. A., The, T., Gardner, M., Fletcher, C., Naravane, A., Gibbs, N., \& Fleishacker, R. (1997). Immunomodulatory activities of Petiveria alliacea L. Phytotherapy Research. 11 (3): 251-253.

Xu, X., Chai, S., Wang, P., Zhang, C., Yang, Y., Yang, Y., Wang, K. (2015). Aldehyde dehydrogenases and cancer stem cells. Cancer letters. 369 (1): 50-57.

Zhu, J., Fan, X., Cheng, Y., Agarwal, R., Moore, C. M., Chen, S. T., Tong, W. (2014). Chemometric analysis for identification of botanical raw materials for pharmaceutical use: A case study using Panax notoginseng. PLoS One. 9 (1): e87462. 